\title{
Quantitative analysis of polycomb response elements (PREs) at identical genomic locations distinguishes contributions of PRE sequence and genomic environment
}

\author{
Helena Okulski ${ }^{1}$, Birgit Druck ${ }^{1,2}$, Sheetal Bhalerao ${ }^{1,3}$, Leonie Ringrose ${ }^{1 *}$
}

\begin{abstract}
Background: Polycomb/Trithorax response elements (PREs) are cis-regulatory elements essential for the regulation of several hundred developmentally important genes. However, the precise sequence requirements for PRE function are not fully understood, and it is also unclear whether these elements all function in a similar manner. Drosophila PRE reporter assays typically rely on random integration by P-element insertion, but PREs are extremely sensitive to genomic position.

Results: We adapted the $\Phi C 31$ site-specific integration tool to enable systematic quantitative comparison of PREs and sequence variants at identical genomic locations. In this adaptation, a miniwhite $(m w)$ reporter in combination with eye-pigment analysis gives a quantitative readout of PRE function. We compared the Hox PRE Frontabdominal-7 (Fab-7) with a PRE from the vestigial (vg) gene at four landing sites. The analysis revealed that the Fab-7 and $v g$ PREs have fundamentally different properties, both in terms of their interaction with the genomic environment at each site and their inherent silencing abilities. Furthermore, we used the $\Phi \subset 31$ tool to examine the effect of deletions and mutations in the $\mathrm{vg}$ PRE, identifying a $106 \mathrm{bp}$ region containing a previously predicted motif (GTGT) that is essential for silencing.

Conclusions: This analysis showed that different PREs have quantifiably different properties, and that changes in as few as four base pairs have profound effects on PRE function, thus illustrating the power and sensitivity of $\Phi$ C31 site-specific integration as a tool for the rapid and quantitative dissection of elements of PRE design.
\end{abstract}

\section{Background}

Polycomb/Trithorax response elements (PREs) are cisregulatory DNA elements that recruit both the Polycomb group (PcG) and Trithorax group (TrxG) proteins, required respectively for gene silencing and activation [1-3]. PREs were first identified in the homeotic gene clusters of the Bithorax complex (BX-C) [4-6] and the Antennapedia complex (ANT-C) [7] in Drosophila. Genomewide studies in flies and vertebrates have since identified several hundred additional PcG target genes involved in cell-fate specification, cell signaling and proliferation [8-18]. However, functional studies of PRE

\footnotetext{
* Correspondence: Leonie.Ringrose@imba.oeaw.ac.at

'IMBA, Institute of Molecular Biotechnology GmBH, Dr. Bohr-Gasse 3, 1030 Vienna, Austria

Full list of author information is available at the end of the article
}

elements themselves have been performed for only a few of these loci. These studies, based on transgenic reporter assays, have shown that several Drosophila PREs share common molecular and genetic features. These include recruitment of PcG and TrxG proteins to an ectopic site, pairing-sensitive silencing (PSS) and variegation of a linked reporter gene, and genetic dependence on the PcG and TrxG proteins $[4-7,19,20]$. Furthermore, several PREs have been shown to act as epigenetic memory elements, conferring mitotic and in some cases meiotic inheritance of the previously established silenced or activated transcriptional states of their associated reporter genes [4-6,21-25]. Recently, two examples of mammalian PREs that share some of these features were reported $[26,27]$. 
The DNA sequence requirements for PRE function are only partially understood. In flies, several DNA motifs have been shown to play an essential role in PcG and TrxG recruitment and in gene silencing or activation at Drosophila PREs. These include binding sites for the PcG proteins Pleiohomeotic (PHO) and PHO-like (PHOL) [28-30], the Zeste protein $(\mathrm{Z})[31,32]$ and the GAGA factor/Trithorax-like (GAF/TRL) [33], which binds a similar motif to that recognized by Pipsqueak (PSQ) $[34,35]$. Clusters of pairs of these motifs are sufficient for computational detection of a subset of known Drosophila PREs and for the prediction of further PREs, many of which have been confirmed experimentally $[8,36]$. However these motifs alone are not sufficient to predict all PREs in the genome, nor to fulfill PRE function [37], and functional roles for additional DNA sequence motifs have been defined for specific PREs, including binding sites for Dorsal switch protein (DSP)1 [37], Grainyhead (GRH) [38], the SP1/Kruppel-like factor (KLF) family of transcription factors [39] and several other unidentified proteins $[1,2,25]$. In addition, with the use of sequence mining, further DNA motifs have been found to be enriched at PRE elements $[8,11]$, and have thus been proposed to play a role in PRE regulation, but their function has not been tested experimentally.

Interestingly, for the functional motifs defined to date, different PREs have different combinations of motifs, with no detectable preferred order or number [8]. Furthermore the order and number of these motifs at PREs is varies greatly between Drosophila species, even within orthologous PREs [36]. These observations raise the question of whether these differences in sequence simply reflect redundancy of design, or whether they are in fact important for determining different functional outputs of different PREs. Several studies support the idea that PREs from different genes are functionally similar to each other despite differences in sequence. For example, transgenic reporter assays in which PREs are linked to a heterologous enhancer have shown that PREs from different Hox genes and from the engrailed gene (en), can maintain reporter-gene expression in the pattern previously determined by the enhancer, showing that these PREs are interchangeable in this maintenance assay $[4,6,25]$. A recent study used gene conversion to examine the effect of exchanging PRE sequences within the BX-C. A 185 bp core sequence of the bxd (bithoraxoid) PRE was replaced within the endogenous Ubx (Ultrabithorax) locus by equivalent core sequences of two PREs from the $A b d-B$ (Abdominal-B) gene. Core sequences were defined as minimal fragments that contain known functional motifs and have PRE activity in reporter assays. The two core PREs tested gave full genetic rescue of the $b x d$ deletion phenotype, again suggesting interchangeability between PRE cores [40].

However there are also results indicating functional differences between PREs from different genes. Genetic experiments have shown that the $U b x$ and $A b d B$ genes respond differently to the removal of PcG proteins upon induction of PcG mutant clones of cells, suggesting different strengths of silencing mediated by the PREs at these loci [41]. For other PREs outside the Hox complexes, several different functions have been documented. For example, the PREs of the polyhomeotic gene ( $p h)$ maintain an equilibrium between activation and silencing instead of an on and off switch as proposed for the Hox PREs $[42,43]$. The hedgehog PRE $(h h)$ has been shown to switch several times during development [24]. A PRE at the Cyclin $(\mathrm{Cyc}) A$ gene mediates PcG-dependent regulation of dynamic $C y c A$ expression during development [44]. These studies indicate that PREs from several different genes have different properties. However, relatively few studies have compared different PREs in the same experimental setup. Furthermore, with the exception of two recent gene-conversion studies reported previously $[40,45]$, most Drosophila PRE studies have relied on transgenic assays using random P-element insertion. This approach has the advantage that it is more rapid than gene conversion, but the disadvantage that PREs are subject to genomic position effects $[4,5,19]$. Thus, to gain a quantitative understanding of differences in PRE function, and to determine the contribution of specific DNA sequences, it is essential to compare PREs, sequence variants and control constructs at the same genomic locus.

We report a quantitative comparison of PREs in Drosophila using the site-specific ФC31 integration tool [46]. We compared the Hox PRE Frontabdominal-7 (Fab-7) from the $A b d-B$ gene with a PRE from the vestigial $(\mathrm{vg})$ locus. To distinguish between the effects of PRE sequence and of genomic environment, we generated transgenic reporter fly lines carrying each PRE at four different, precisely characterized, landing sites. This analysis demonstrates that the Fab-7 and $v g$ PREs do indeed have inherently different properties, in terms of their ability to silence the reporter gene, the extent of pairing sensitivity and their interaction with the genomic environment. For the $v g$ PRE, we present a mutational analysis, identifying an essential function in silencing for a motif (GTGT) that was previously discovered by bioinformatic sequence mining to be enriched at many PRE sites [8]. In summary, this study gives quantitative insights into the similarities and differences in PREs from distinct genes, and identifies DNA sequences essential for silencing. Thus, site-specific ФC31 integration offers a powerful approach for the rapid and quantitative dissection of elements of PRE design. 


\section{Results}

Site-specific integration enables analysis of PREs at known genomic locations

To enable quantitative comparison of PREs and their variants, and to avoid the problem of genomic position effects, we adapted the $Ф C 31$ site-specific integration system to make it suitable for comparative studies of PREs at the same genomic location (Figure 1) [46]. To this end we used an adaptation of the 'split white' system [47], in which a functional white gene $(w)$ is reconstituted only upon the correct site-specific integration event. We replaced the white gene with miniwhite ( $m w$; FBtp0000155). The $m w$ gene contains the coding sequences of the white gene, but the 5 " regulatory sequences are reduced to $300 \mathrm{bp}$. The $m w$ gene is typically used as a sensitive reporter gene for PRE effects [5], and serves here both as a transgenic marker and as a reporter of PRE activity.

Landing-site fly lines were generated by standard Pelement integration into $y w$ flies, using yellow $(y)$ as a transformation marker, and their genomic locations were mapped (Table 1). The landing site carries an attP site followed by a genomic DNA fragment of the white gene containing the last 205 bp of intron 1, and the remaining downstream exons. The landing-site lines used here for comparative studies of PREs were selected by means of two criteria: no Polycomb protein binding within a window of $\pm 5 \mathrm{~kb}$ from the landing site $[9,11]$, and an intergenic location (Table 1). The donor plasmid, pKC27_mw, carries the $m w$ promoter, followed by exon 1, the first $195 \mathrm{bp}$ of intron 1, and an attB site (Figure 1A). Upon site-specific integration of $\mathrm{pKC} 27 \_m w$ into the landing site, a functional $m w$ gene is reconstituted with the attB/attP site in the intron (Figure 1B). PREs were cloned into the $\mathrm{pKC} 27 \_m w$ plasmid directly upstream of the $m w$ reporter gene (Figure 1A). Transgenics were generated (described in Methods), by coinjection of landing-site lines with $\mathrm{pKC} 27 \_m w$ derivatives and a helper plasmid encoding the ФC31 integrase. Flies carrying only the $m w$ reporter had red eyes (Figure $1 B)$. In the presence of a PRE, the eye color gives a readout of the PRE activity at the same landing site. Typically, addition of a PRE sequence led to downregulation of $m w$ (Figure 1B). In summary, site-specific integration combined with an $m w$ reporter enables comparison of PREs and control constructs at the same genomic loci.

\section{A $1.6 \mathrm{~kb}$ fragment of the vestigial PRE is sufficient to mediate Polycomb-dependent silencing}

The site-specific integration tool enables not only the comparison of PREs and control constructs at the same genomic location, but also the comparison of different PREs. We chose to compare the well-characterized Fab-7 PRE from the BX-C with a less well-characterized PRE from outside the Hox complexes, namely, from the vestigial $(v g)$ gene. The $v g$ gene is essential for correct cell-fate specification in wing and haltere development [48] and during muscle differentiation [49,50], and is also expressed in the embryonic central nervous system [48,51].

The $F a b-7$ PRE regulates the homeotic gene $A b d-B$, and is located downstream of the gene, approximately $70 \mathrm{~kb}$ from the promoter [52,53]. Similarly, the $v g$ PRE that we studied is located downstream of the gene, approximately $20 \mathrm{~kb}$ from the promoter (Figure $2 \mathrm{~A}, \mathrm{~B}$ ). This $v g$ PRE was identified by bioinformatic prediction

\section{A}

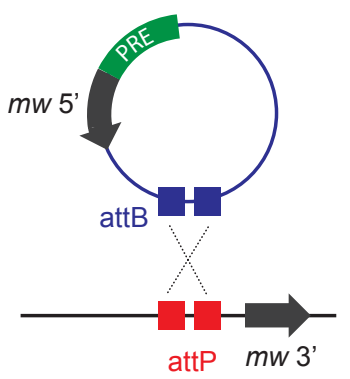

B
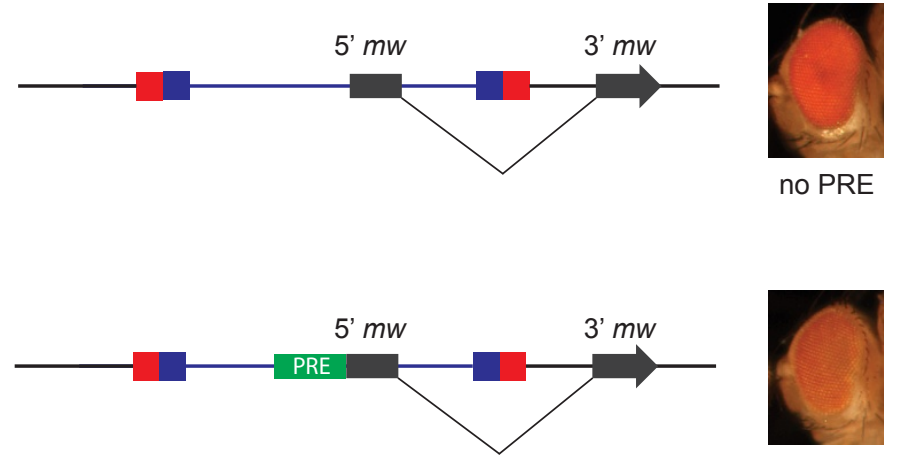

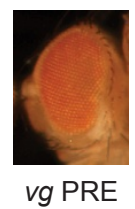

Figure 1 Comparison of Polycomb response elements (PREs) by $\Phi C 31$ site-specific integration. (A) The plasmid pKC27 carries the PRE of interest, the $5^{\prime}$ end of the miniwhite $(\mathrm{mw}$ ) reporter gene including the first exon and $195 \mathrm{bp}$ of the first intron and the phage $\Phi \mathrm{C} 31$ attB recognition site. The genomic landing site carries an attP site followed by a genomic DNA fragment of the white gene containing the last 205 bp of intron 1 and the remaining downstream exons. (B) Correct site-specific integration is detected by the expression of a functional mw reporter gene. (Top right) flies carrying only the $m w$ reporter have red eyes. (Bottom right) The $m w$ reporter is repressed in the presence of a $\mathrm{PRE}$, resulting in a decrease in eye coloration. 
Table 1 Characteristics of landing sites ${ }^{1}$

\begin{tabular}{|c|c|c|c|c|c|c|c|c|c|}
\hline Site & $\begin{array}{l}\text { Cytological } \\
\text { location }^{2}\end{array}$ & $\begin{array}{l}\text { Genomic } \\
\text { location }^{2} \\
\end{array}$ & $\begin{array}{l}\text { Gene } \\
\text { density }^{3}\end{array}$ & $\begin{array}{l}\text { Adjacent } \\
\text { genes }^{4}\end{array}$ & $\begin{array}{l}\text { Next PC binding } \\
\text { sites }^{5}\end{array}$ & $\begin{array}{l}\text { Chromatin } \\
\text { type }^{6}\end{array}$ & GTGTG $^{8}$ & GAGAG $^{8}$ & GCCAT $^{8}$ \\
\hline \multirow[t]{2}{*}{1} & chr. 2L, 38E3 & $20,716,266$ & 2 & +8 kb: CG9316 & +42 kb: dia & Red & 59 & 36 & 51 \\
\hline & & & & $-1.7 \mathrm{~kb}: \mathrm{Hr} 38$ & -947 kb: bsh & & & & \\
\hline \multirow[t]{2}{*}{2} & chr. 2R, 46E1 & $5,965,083$ & 4 & $+0.8 \mathrm{~kb}:$ egr & +1396 kb: inv & Red & 47 & 25 & 53 \\
\hline & & & & -1.9 kb: CG1371 & -97 kb: eve & & & & \\
\hline \multirow[t]{2}{*}{3} & chr. 2R, 58F4 & $18,549,410$ & 12 & $\begin{array}{l}\text { +29 bp: } \\
\text { CG42566 }\end{array}$ & $+205 \mathrm{~kb}: f d 59 \mathrm{~A}$ & Blue & 43 & 26 & 36 \\
\hline & & & & $\begin{array}{l}-0.5 \mathrm{~kb}: \\
\text { CG42565 }\end{array}$ & $-375 \mathrm{~kb}: d v e$ & & & & \\
\hline \multirow[t]{2}{*}{4} & chr. 3R, 100E3 & $27,899,491$ & 1 & $\begin{array}{l}\text { Telomeric } \\
\text { region }\end{array}$ & - & Yellow & 41 & 38 & 17 \\
\hline & & & & $\begin{array}{l}-5.3 \mathrm{~kb}: \\
\text { Map205 }\end{array}$ & -5.3 kb: Map205 & & & & \\
\hline
\end{tabular}

\footnotetext{
${ }^{1}$ All four landing sites are located in intergenic regions with no PcG binding within a window or $\pm 5 \mathrm{~kb}[9,11]$.

${ }^{2}$ Cytological and genomic locations are shown according to FlyBase version FB2010_05.

${ }^{3}$ Gene density: number of genes whose gene span overlaps a $\pm 10 \mathrm{~kb}$ window from the landing site.

${ }^{4}$ Adjacent genes: distance between genomic coordinate of the landing site and that of the closest edge of the next adjacent gene span in both directions (- = upstream, $+=$ downstream according to genomic coordinates). Note that site 3 is located in the telomeric region of chromosome $3 \mathrm{R}$, thus there is no downstream gene.

${ }^{5}$ Next PC binding sites: the closest Polycomb binding site up and downstream of the landing site was identified according to [9,11].

${ }^{6}$ Chromatin type: Drosophila chromatin type according to [66] in which each landing site is located. 'Red' and 'yellow' chromatin types share features of transcriptionally active euchromatin but differ in the presence of specific factors (see Discussion for details). Note that the border of 'yellow' chromatin extends to $1.7 \mathrm{~kb}$ upstream of site 4 . This site is not assigned to a chromatin type in [66]. 'Blue' chromatin is enriched for PcG proteins and H3K27me3.

${ }^{8}$ GTGTG, GAGAG, GCCAT: the number of occurrences of each of these motifs within $10 \mathrm{~kb}$ up and downstream of each landing site is shown.
}

and confirmed as a PcG binding site by chromatin immunoprecipitation (ChIP) [8] (Figure 2A). A 3 kb fragment containing the highest-scoring region shown in Figure $2 \mathrm{~A}$ has previously been verified as a PRE in transgenic reporter assays [54]. Later genomewide profiling studies showed that both this $v g$ PRE and the $v g$ promoter are enriched for PcG and/or TrxG proteins in Drosophila cell culture $[9,10,16]$, in embryos $[11,55]$ and in larval imaginal discs [55]. The promoter site also contains GAF, ZESTE and PHO binding sites (observable by the peak at this site in the score plot on Figure 2A), but has not been verified as a PRE in transgenic assays. Thus, we focused our analysis on the downstream $v g$ PRE.

Comparison of this $v g$ PRE with the Fab-7 PRE in terms of the occurrence of DNA-binding motifs identified a distinct number, density and distribution of motifs (Figure 2C; see Additional file 1, Figure S1). Transgenic studies of the Fab-7 PRE identified a minimal 219 bp fragment that is sufficient for PRE activity [56], (see Additional file 1, Figure S1). This fragment falls within the highest-scoring region in computational predictions, based on the density of pairs of GAF, ZESTE and PHO binding sites [8]. However the sequences flanking this fragment contain additional binding sites for these proteins, thus we cloned $1.6 \mathrm{~kb}$ of the Fab-7 PRE sequence, centered on the minimal PRE (see Additional file 1, Figure S1). The minimal functional fragment of the $v g$ PRE has not been defined, but the site of highest motif density is identifiable as the highest-scoring region in the study by Ringrose et al. [8] (Figure 2C, grey box), thus to enable comparisons with the Fab-7 PRE, we cloned $1.6 \mathrm{~kb}$ of the $v g$ PRE centered on this site. This $1.6 \mathrm{~kb}$ fragment falls within the $3 \mathrm{~kb}$ fragment previously shown to fulfill PRE function [54].

To test whether this $1.6 \mathrm{~kb}$ PRE fragment is also able to accomplish Polycomb-dependent silencing, we crossed transgenic flies carrying pKC27_mw either with or without the $1.6 \mathrm{~kb} v g$ PRE at landing sites 1,2 or 3 (Table 1) into a Polycomb (Pc) mutant background (Figure 2D). In the wild-type background, addition of the PRE to the $m w$ reporter caused repression of $m w$ at all three landing sites (Figure 3D, top row, Figure 4). Control flies (no PRE), heterozygous or homozygous for the $m w$ reporter, showed no change in a $P c^{X L 5}$ mutant background at all three sites (Figure 2D and data not shown). Likewise, flies heterozygous for the $v g$ PRE showed no detectable change in the $P c^{X L 5}$ mutant background (data not shown). By contrast, flies homozygous for the $v g$ PRE showed a loss of silencing at all three sites in the $P c^{X L 5}$ mutant background, indicated by an increase in eye pigmentation (Figure 2D, bottom row). In summary, these results show that the $1.6 \mathrm{~kb} v \mathrm{PRE}$ functions as a Polycomb-dependent silencer.

\section{The $v g$ and Fab-7 PREs show site-specific differences in silencing behavior}

To determine whether the $v g$ and Fab-7 PREs have inherently different functions, we used the $Ф C 31$ site-specific 


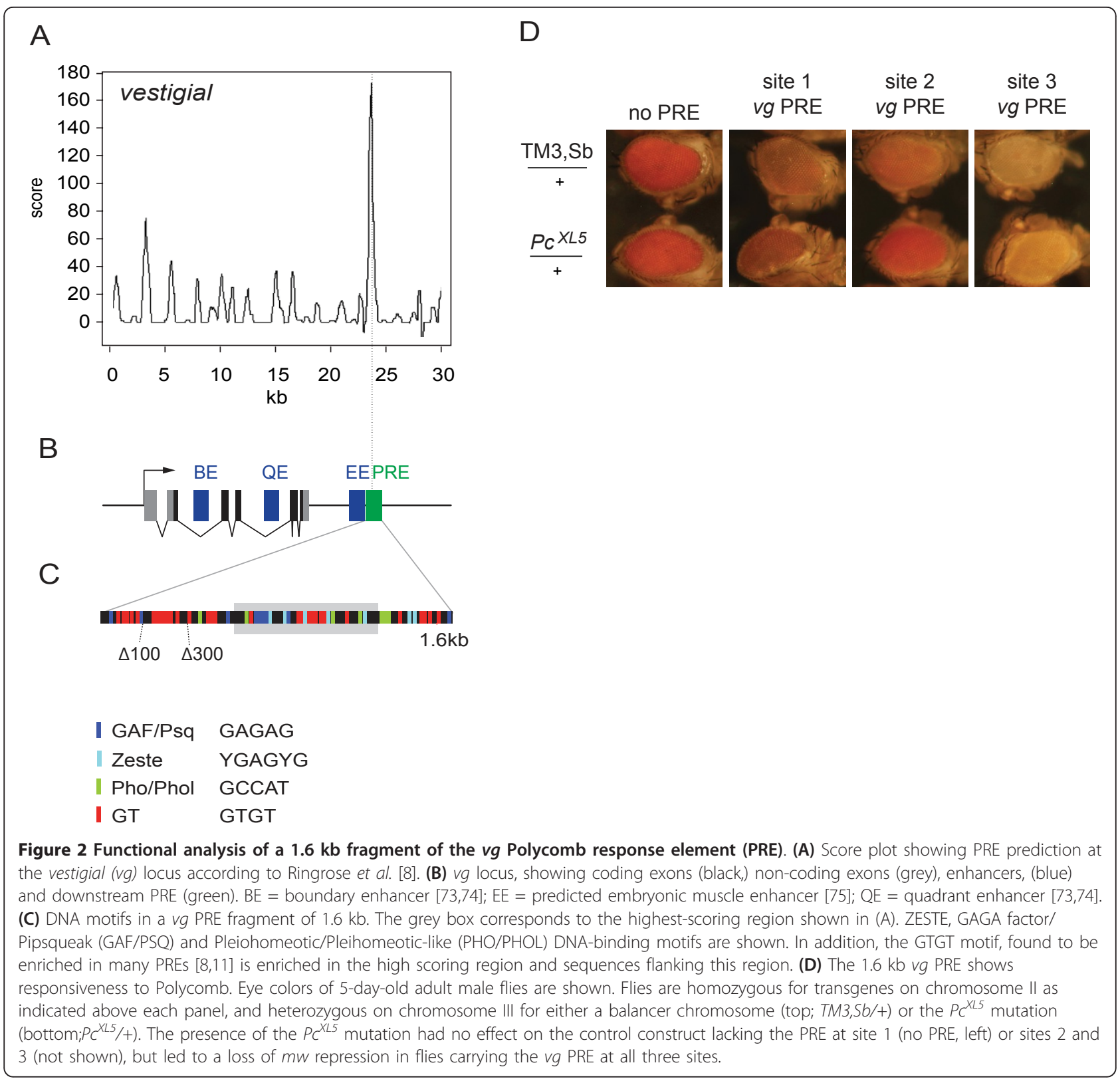

integration tool to perform a quantitative comparison of the $1.6 \mathrm{~kb} v g$ and Fab-7 PREs. To distinguish between the effects of genomic environment and the inherent properties of the PRE sequence, we compared the PREs to control constructs lacking the PRE at each of the four landing sites (Table 1). To obtain a quantitative readout of $m w$ expression levels, we extracted and measured the eye pigment from the heads of 5-day-old flies for each transgenic line, from flies both heterozygous and homozygous for the transgene (Figure 3 ).

To determine the effect of the genomic environment on the level of $m w$ activity in the absence of the PRE, we first examined the control lines at each landing site
(Figure 3A,B (no PRE)). Surprisingly, three of the four transgenic lines had strong pairing-sensitive activation (PSA) of $m w$ in the absence of the PRE. The expected expression level of the $m w$ reporter gene was twofold lower in heterozygotes (carrying one copy of the $m w$ gene) compared with homozygotes (carrying two copies of the $m w$ gene). This was seen at site 4 , where heterozygotes had $7 \%$ and homozygotes $13 \%$ of wild-type pigment levels (Figure 3B). However, at sites 1, 2 and 3, the homozygous pigment levels were four to 12 times higher in heterozygotes (Figure 3B). This suggests a pairing-dependent activation of the $m w$ reporter at sites 1, 2 and 3, and gives a quantitative measure of the 


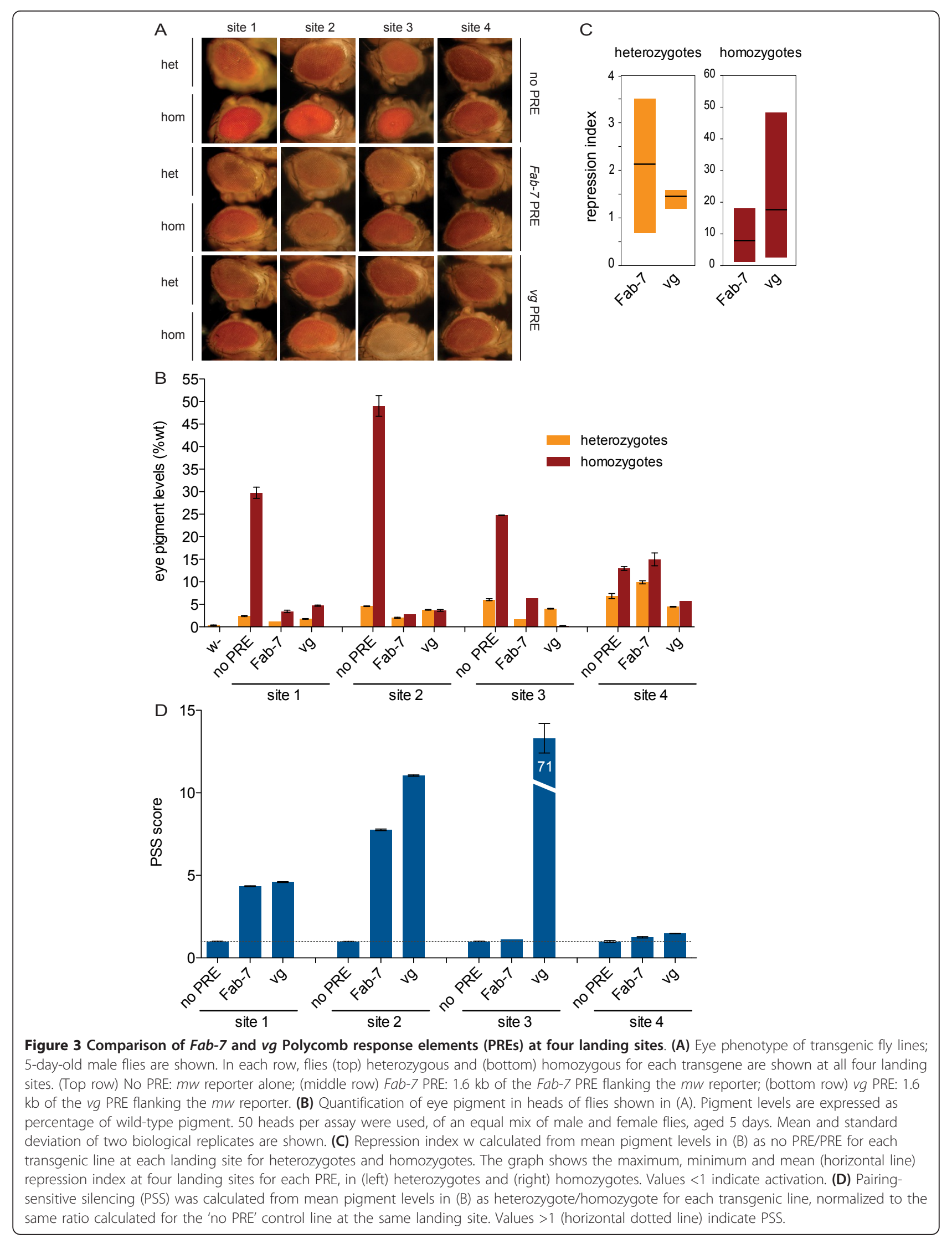


extent to which the genomic environment of the landing sites affects $m w$ reporter-gene activity in the absence of a PRE.

We next quantified the effect of each PRE on the $m w$ levels at each landing site (Figure 3B). This analysis revealed PRE- specific effects at each site. For example, in both heterozygotes and homozygotes at sites 1 and 2, the Fab-7 PRE repressed $m w$ more strongly than the $v g$ PRE, but at site 4, the reverse was true. Indeed, $F a b-7$ gave higher levels of $m w$ than the control line at site 4, indicating that this element acts as an activator at this site. Remarkably, at site 3, opposite effects were observed for the two PREs in heterozygotes and homozygotes, with the $v g$ PRE giving weaker repression than the Fab-7 PRE in heterozygotes, but stronger repression in homozygotes. These site-dependent differences in silencing strength clearly indicate that the two PREs interact differently with the genomic environment of each landing site.

These observed site-specific differences in PRE behavior raised the question of whether the Fab-7 and $v g$ PREs have intrinsic properties that are inherent to each PRE despite the effect of genomic environment. To address this question, we calculated a 'repression index' for each PRE, and used this to compare their general behavior in heterozygotes and homozygotes (Figure 3C). The repression index is defined as the ratio of 'no PRE' to 'PRE' pigment levels at each site, thus a higher repression index indicates stronger silencing. Figure 3C shows the minimum, maximum and mean repression index for all four sites for each PRE in heterozygotes and homozygotes (values $<1$ indicate activation). Surprisingly, this analysis revealed striking differences in the properties of the Fab-7 and $v g$ PREs in heterozygotes and homozygotes. In heterozygotes (Figure 3C, left panel), the effects of Fab-7 PRE on $m w$ differed strongly from site to site, ranging from a 3.5 -fold repression to a 1.5 -fold activation. The wide range of values for $\mathrm{Fab}-7$ in heterozygotes indicates high sensitivity of $\mathrm{Fab}-7 \mathrm{PRE}$ to the landing-site environment, and an ability to silence strongly at some sites but to activate at one site. By contrast, the narrow range of values for the $v g$ PRE in heterozygotes, with a mean at approximately 1.5 -fold repression (Figure 3C, left panel) indicates that this PRE was less sensitive to its genomic environment than $F a b$ 7 , giving mild silencing of $m w$ at all sites tested. (Figure 3C, left panel).

In homozygotes, this tendency was reversed (Figure $3 \mathrm{C}$, right panel). Although the silencing properties of both PREs were typically stronger in homozygotes than in heterozygotes, the Fab-7 PRE showed less repression on average, ranging from 18-fold repression to 1.2 -fold activation, compared with the $v g$ PRE, which ranged from 49-fold to 2.3-fold repression. Furthermore, the $v g$ PRE had more site-dependent variation than Fab-7, indicating a higher sensitivity to the genomic environment at the four sites tested (Figure 3C, right panel). In summary, this analysis indicates that the $v g$ and Fab-7 PREs do indeed have inherently different properties in terms of their ability to repress the $m w$ reporter in the heterozygote and homozygote states, and their sensitivity to genomic environment in each of these states.

To further evaluate differences in PRE behavior, we examined PSS, a phenomenon typical of Drosophila PREs $[19,20]$. In PSS, the reporter gene is more strongly repressed in flies homozygous for a PRE transgene than in flies heterozygous for the same PRE transgene. PSS is thought to be caused by PcG proteins forming higherorder complexes on paired PREs. We used the eye-pigment assay data to define a quantitative 'PSS score', by calculating the ratio of heterozygote to homozygote eye pigment for each PRE line, and normalizing these values to the same ratio calculated for the 'no PRE' control at the same landing site, for which we assumed no PSS. Thus, a PSS score close to 1 indicates that the ratio of homozygous to heterozygous eye pigment is similar to that of the 'no PRE' line, and thus that there is no or only very weak PSS (Figure 3D); for example, this was the case for Fab-7 at sites 3 and 4 and $v g$ at site 4 (Figure 3D). By contrast, we found strong PSS for both PREs at sites 1 and 2. Intriguingly, these site-specific PSS scores agree well with the PSA levels we found for the 'no PRE' construct, suggesting that the inherent pairing properties of each locus may influence the extent to which PRE-dependent PSS occurs. However, we also found a striking difference between the $F a b-7$ and $v g$ PREs at site 3 . Whereas the Fab-7 PRE had a PSS score of 1.1 at this site,(indicating no PSS) the $v g$ PRE had a PSS score of 71 (Figure 3D) with homozygous flies displaying completely white eyes (Figure 3A).

Taken together, these results indicate quantitative differences in the behavior of the $v g$ and Fab-7 PREs in terms of reporter-gene repression and PSS, which reflect both specific interactions of each PRE with the genomic environment at each landing site, and the inherent properties of each PRE.

\section{Deletion analysis of the $v g$ PRE identifies sequences essential for PRE function}

A set of motifs consisting of the ZESTE, GAF/PSQ and $\mathrm{PHO} / \mathrm{PHOL}$ binding sites are necessary, but not sufficient for PRE function [37]. Sequence mining has revealed a novel motif frequently found in predicted PREs, termed the GTGT motif [8]. This motif has also been found independently to be enriched in genomewide ChIP datasets [11], but has not been tested experimentally. The $1.6 \mathrm{~kb} v g$ PRE is highly enriched in this motif (Figure 2C) To investigate whether GTGT repeats play a role in PRE function, we generated deletion 


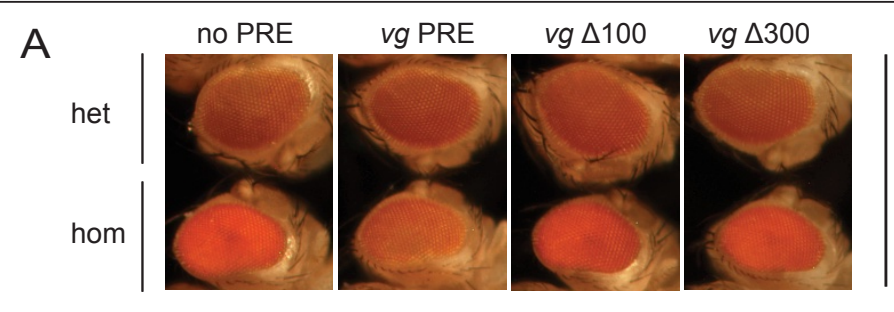

site 2

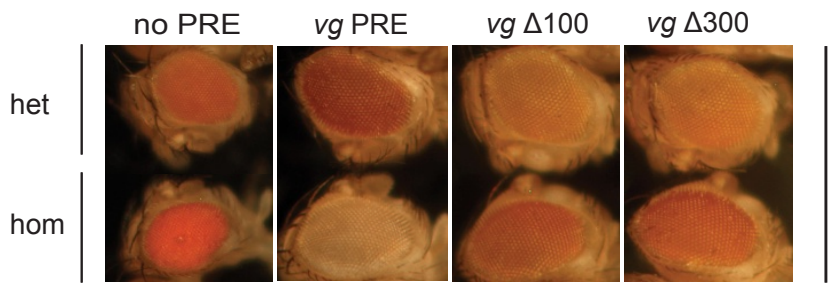

site 3

B

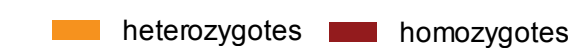

C
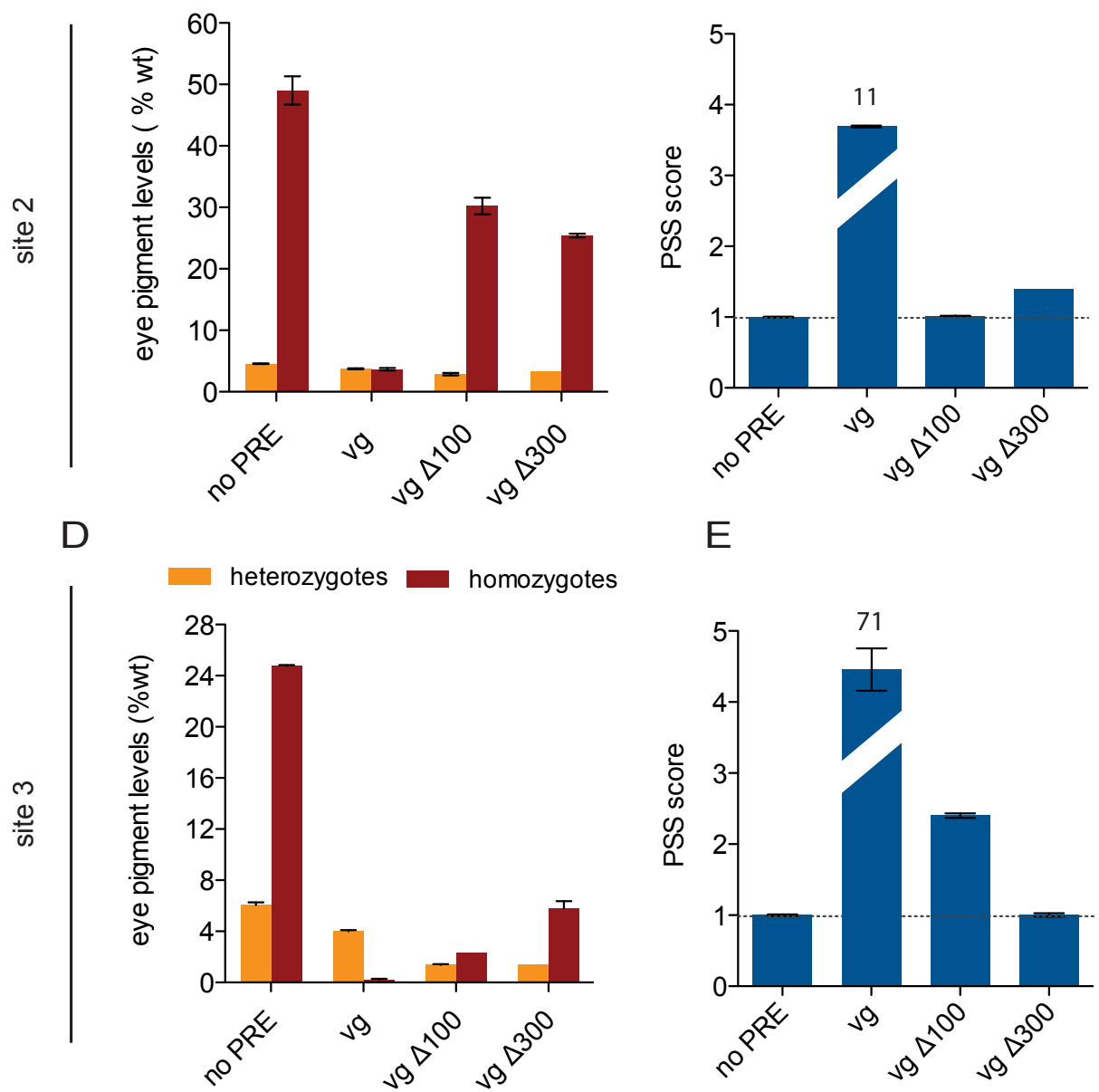

\section{E}

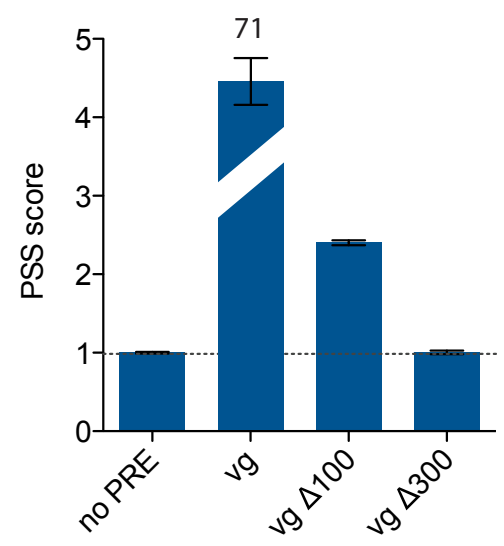

Figure 4 Deletion analysis of the $\mathbf{v g}$ Polycomb response element (PRE). (A) Eye phenotype of transgenic fly lines; 5-day-old male flies are shown. In each row, (top) heterozygous and (bottom) homozygous transgenic flies are shown, carrying the mw reporter alone (no PRE), the 1.6 $\mathrm{kb} v \mathrm{~g}$ PRE, a deletion of the first $106 \mathrm{bp}(\mathrm{vg} \Delta 100)$ and the first $291 \mathrm{bp}(\mathrm{vg} \Delta 300)$ of the $1.6 \mathrm{~kb} v \mathrm{~g}$ PRE, at landing sites (top) 2 and (bottom) 3 . (B, D) Quantification of pigment levels of the heterozygous and homozygous transgenic $v g \Delta 100$ and $v g \Delta 300$ deletion lines at landing sites (B) 2 and (D) 3. (C,E) Pairing-sensitive silencing (PSS) of transgenic $v g \Delta 100$ and $v g \Delta 300$ deletion lines at landing sites (C) 2 and (E) 4, calculated as in Figure 3. 
constructs lacking sequences containing these motifs (Figure 2C). The $v g \Delta 100$ construct lacks the first 106 bp, containing the first block of GTGT repeats, and $v g \Delta 300$ lacks the first $291 \mathrm{bp}$ of the $1.6 \mathrm{~kb} v g$ PRE, containing the first and second blocks of GTGT repeats. As the $v g$ PRE had the strongest PSS at sites 2 and 3 (Figure $3 \mathrm{D}$ ), the deletion constructs were integrated at these sites. The effects of deletions were evaluated by pigment assay and PSS score as described above.

At site 2, at which the $1.6 \mathrm{~kb} v g$ PRE caused partial repression of $m w$ in homozygotes, the $v g \Delta 100$ deletion line had little effect on reporter-gene activity in heterozygotes, but a pronounced loss of silencing in homozygotes (Figure 4B) and a complete loss of PSS (Figure $4 \mathrm{C})$. These effects were not increased by further deletion in the $v g \Delta 300$ constructs (Figure 4B,C). Similarly, at site 3 , at which the $1.6 \mathrm{~kb} v g$ PRE caused complete repression of $m w$ in homozygotes, the $v g \Delta 100$ homozygotes had partial loss of silencing and PSS, whereas the $v g \Delta 300$ homozygotes had a more pronounced loss of silencing and total loss of PSS (Figure 4A,D,E). Remarkably, in heterozygotes at site 3 , both the $v g \Delta 100$ and $v g \Delta 300$ deletion lines had an increase in silencing compared with the $1.6 \mathrm{~kb} v g$ PRE (Figure 4A,D). In summary, by comparing the same deletion constructs at two different landing sites, this analysis distinguished between landing site-specific effects of the deletions such as those seen in heterozygotes at site 3 , and effects that are intrinsic to the PRE sequences themselves, such those seen in homozygotes at both sites. The fact that the deletion of the first 106 bp leads to loss of repression in homozygotes at both sites demonstrates that this sequence is essential for PRE function.

\section{The GTGT motif is essential for $v g$ PRE silencing}

The $v g \Delta 100$ deletion removed several GTGT repeats and a single GAGA motif (Figure 2C, Figure 5A). To gain further insight into the role of this GAGA site and the GTGT repeats in PRE silencing function, we used site-directed mutagenesis to generate $v g$ PRE constructs with deletions of single motifs or groups of motifs (Figure 5A) within the first $106 \mathrm{bp}$ of the $1.6 \mathrm{~kb} v g$ PRE. All constructs were integrated at sites 2 and 3 .

We first addressed the role of the GAGA motif (Figure 5A). The GAF protein or GAGA binding motifs have been reported to be required for activation or silencing, or to be dispensable at different PREs [57]. In heterozygotes, $v g \Delta$ GAGA lines in both sites 2 and 3 produced a loss of silencing of 1.4-fold to twofold compared with the $1.6 \mathrm{~kb} v g$ PRE line. However, deletion of the GAGA site had no detectable effect on the PRE silencing function in homozygotes at either site (Figure $5 B-E)$, thus the GAGA site cannot account for the pronounced loss of silencing seen in homozygotes of the $v g \Delta 100$ deletion lines (Figures 4, Figure 5C,E).

We next addressed the role of the GTGT repeats. Deletion of the first GTGT repeat $\left(v g \Delta 1^{\text {st }} \mathrm{GT}\right)$ at site 2 resulted in a substantial loss of silencing in both heterozygotes (twofold) and homozygotes (threefold), resulting in a twofold reduction in PSS (Figure 5B-D). Replacement of the GTGT sequence with a different sequence led to similar loss of silencing, indicating a specific requirement for the GTGT motif (not shown). Strikingly, deletion of the first and the second GTGT repeat $\left(v g \Delta 1^{\text {st }}-2^{\text {nd }} \mathrm{GT}\right)$ had no further effect in heterozygotes but a dramatic (7.5-fold) loss of silencing in homozygotes, similar to that seen with the $\Delta 100$ deletion (Figure 5B-D). Deletion of further GTGT repeats did not lead to further loss of silencing, thus this analysis identified an essential contribution of the first two GTGT repeats at this site. These observations were further reflected in PSS levels (Figure 5D).

To evaluate whether the loss of silencing seen upon deletion of GTGT repeats reflects a PRE-specific requirement, or rather an interaction of these motifs with the genomic environment of the landing site, we analyzed the same series of deletion constructs at site 3 . Remarkably, despite the strong silencing in the homozygous $1.6 \mathrm{~kb}$ PRE line at site 3 , the trend for the GTGT deletion series was similar to that seen for site 2 (Figure 5B, E, S2). At site 3, all GTGT repeat deletion lines had 1.2-fold to 1.5-fold higher pigment levels in heterozygotes than in the $1.6 \mathrm{~kb} v g$ PRE (Figure 5B,E). Homozygous pigment levels increased 2.4-fold upon deletion of the first or first and second GTGT. In contrast to site 2, additional deletion of the third GTGT repeat resulted in a further loss of silencing of fourfold (Figure 5E; see Additional file 2, Figure S2). Additional deletion of the fourth GTGT repeat had no further effect on silencing (Figure 5E). These observations were also reflected in the PSS score, with successive deletion of the GTGT repeats resulting in a gradual decrease in PSS (Figure 5F). Thus, although the $v g$ PRE acts as a strong silencer at site 3 , this repression is partly relieved by deletion of the GTGT motifs. Taken together, these results show that the GTGT motif plays an essential role in $v g$ PRE silencing function at both genomic loci tested.

\section{Discussion}

Classic Drosophila PRE assays have used random integration by P-element insertion. However PREs are extremely sensitive to genomic position, thus comparisons between different elements and evaluation of the effect of mutations, has previously relied upon average behavior of multiple different transgenic lines [37,43]. In this study, we used the ФС31 site-specific integration tool to 


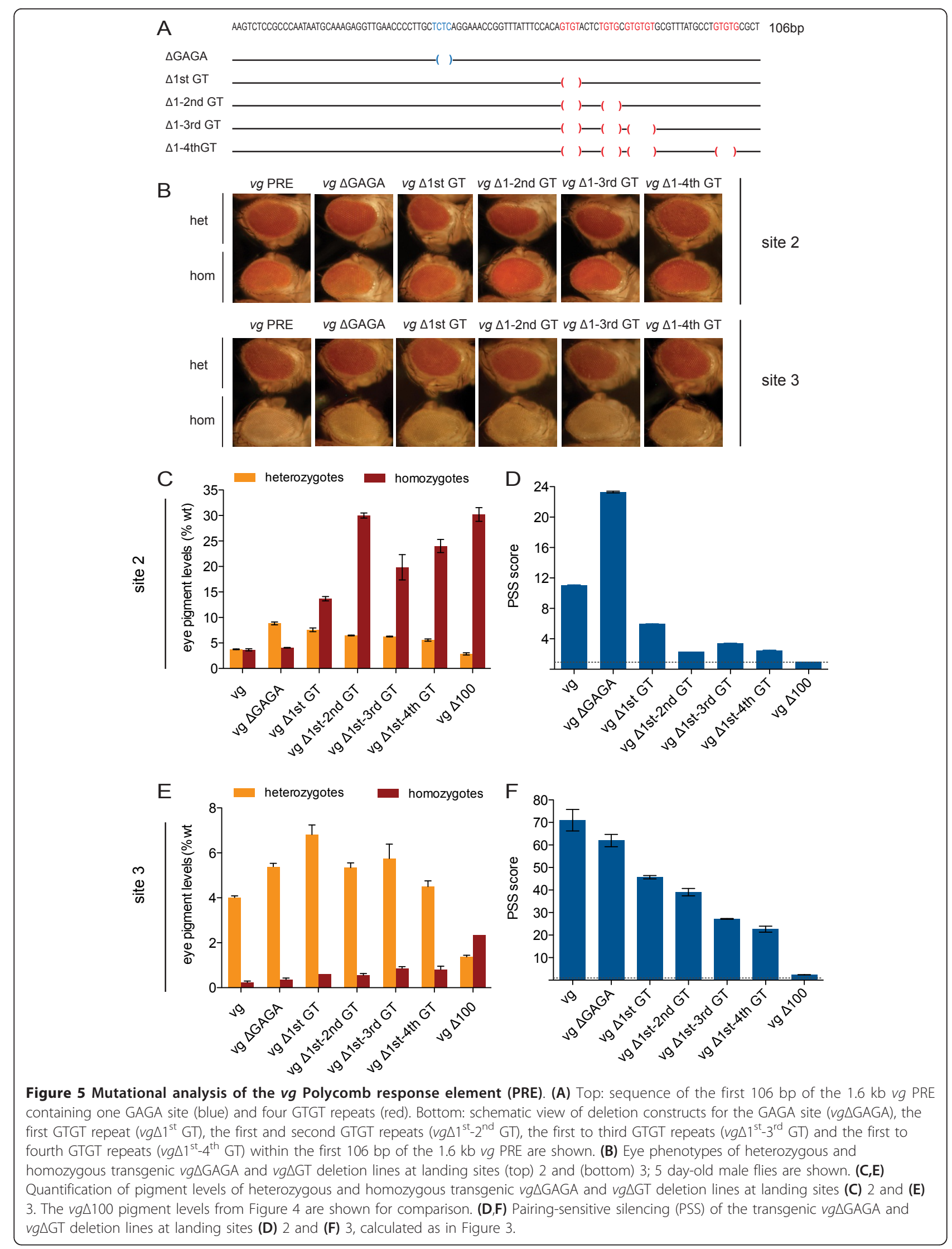


compare different PRE elements, mutated variants and control constructs at identical genomic locations, enabling quantitative comparisons.

\section{Inherent properties of Fab-7 and $v g$ PREs}

In addition to differences in their interaction with the landing-site environment (discussed below), the quantitative analysis presented here revealed surprising differences in the inherent properties of the two PREs, in terms of their influence on reporter genes in the heterozygote and homozygote states (Figure 3C). Whereas the Fab-7 PRE had a wide range of reporter-gene expression levels at the four sites in heterozygotes and a more uniform output in homozygotes, this trend was reversed for the $v g$ PRE, which gave a uniform mild silencing at all sites in heterozygotes, in contrast to the wide site-to-site differences in levels of reporter-gene activity in homozygotes. The data in heterozygotes suggest that the Fab-7 PRE may be more sensitive to cis effects whereas, the $v g$ PRE seems to buffer against them. This demonstration of different PRE properties is consistent with several studies showing differences in PRE behavior [24,42-44]. It would be of great interest in future to use the sitespecific quantitative approach described here for the systematic comparison of other PREs.

We quantified the extent to which each PRE mediates PSS at each site. Interestingly, both the BX-C and the endogenous $v g$ locus have been shown to be subject to transvection, in which the expression of a gene can be affected by its homologous counterpart in trans $[58,59]$. In the case of the BX-C, several PREs, including the Fab-7 PRE [60] have been shown to be able to mediate trans effects, but the transvection observed at the endogenous $v g$ locus [59] has not been attributed to specific sequences. The strong PSS we found for the $v g$ PRE at sites 1, 2 and 3 suggests that this element may play a role in the transvection properties of the $v g$ locus.

The quantitative analysis presented here identified important differences between the Fab-7 and $v g$ PREs. The molecular mechanisms that underlie these differences will be a key question for future studies. A recent study in which core sequences of Hox PREs were exchanged at the same genomic location has shown that these sequences can effectively substitute for each other [40], raising the possibility that Hox PREs are rather similar, and that the differences we found could be due to the comparison of Hox and a non-Hox PRE. However, in experiments with a $1.6 \mathrm{~kb}$ fragment of the Hox $b x d$ PRE, we found different levels of silencing to Fab-7 at all sites tested, and were able to recover transgenes at some sites only by PCR screening, owing to strong silencing in heterozygotes (data not shown). Thus, we propose that the difference between Fab-7 and $v g$ PREs that we found lies less in a fundamental difference between
Hox and non-Hox PREs than in differences between the sequences flanking the core region.

\section{Site-specific differences between Fab-7 and $v g$ PREs}

Genomic position effects on PRE behavior have been found in studies using random P-element insertion of PRE reporter transgenes $[4,5,19]$. However, it has not been clear whether these effects are due to the general transcriptional activity at a given site or whether each PRE interacts specifically with local genomic features. Our data strongly support the latter interpretation, because the Fab7 and $v g$ PREs showed strikingly different behaviors at each site. These differences were most pronounced at site 3, at which the Fab-7 PRE showed no evidence of no PSS whereas the $v g$ PRE had a PSS score of 71 (71-fold PSS) (Figure 3D), and at site 4, at which the Fab-7 PRE induced activation, whereas the $v g$ PRE induced repression of the reporter gene (Figure 3B). These results clearly indicate PRE-specific interactions with the genomic environment at each site, and suggest that sequences within each PRE may be interacting with a selected set of enhancers and/or repressors (Figure 6).

This interpretation is consistent with a recent study of an engrailed PRE reporter inserted at different sites by random P-element insertion [61], showing that the reporter gene reflects patterns of nearby enhancers in a PREdependent manner. Our work provides a further example of selective interaction of PREs with their genomic environment, and raises the intriguing possibility that different PREs may interact preferentially with different regulatory elements (Figure 6). We have focused here on the quantitative analysis enabled by the $m w$ reporter combined with the pigment assay, thus limiting our study to the readout in the adult eye. However, it would also be of great

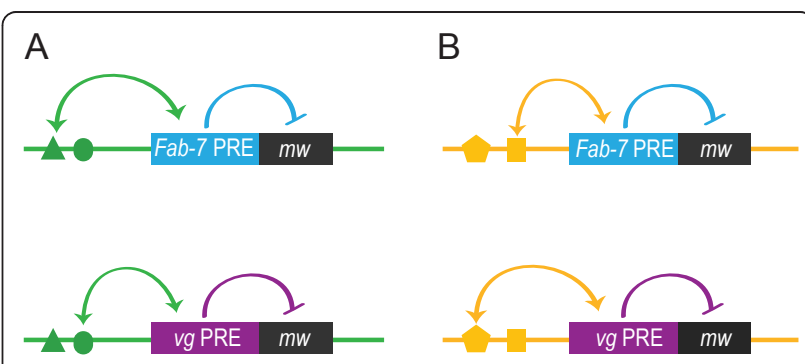

Figure 6 Polycomb response elements (PREs) show both sitespecific and inherent behavior. The Fab-7 (blue) and $v g$ (purple) PREs are shown at two different landing sites $(\mathbf{A}, \mathbf{B})$. Each PRE has inherent properties in repressing the $m w$ reporter (blue and purple arrows). We propose that each PRE also interacts specifically with different enhancers or repressors at each landing site (green and yellow arrows; enhancers/repressors shown as solid symbols). The output of the mw promoter depends on the properties of the PRE, on its interaction with the landing-site environment, and on whether the PRE is heterozygous or homozygous (see main text for details). 
interest to determine whether the $F a b-7$ and $v g$ reporters are expressed in distinct patterns during development at each landing site, as this would reveal whether the quantitative differences between the two PREs that we observed indeed reflect specific interactions with different regulatory elements at each landing site. As our constructs did not contain a $L a c Z$ reporter (similar to those reported previously [61]), this analysis would require in situ hybridization to the $m w$ cDNA.

\section{Inherent properties of landing sites}

Despite PRE-specific differences in behavior, some characteristics of each landing sites did seem to be reflected by both PREs. For example, we found that at sites 1, 2 and 4, the extent of PSS shown by each PRE closely mirrored the extent of PSA of the reporter gene lacking the PRE (Figure 3D). This observation emphasizes the advantage of examining control constructs and PRE constructs at identical locations, enabling a quantitative evaluation of the contribution of both the locus itself and the PRE sequences to pairing-dependent effects. At sites 1 and 2, we found strong PSA and strong PSS by both PREs, whereas at site 4, we found no PSA and little or no PSS by either PRE. Pairing of homologous chromosomes occurs in somatic cells in Drosophila, and can facilitate both activation and repression of genes $[62,63]$. It has been proposed that PSS, commonly observed for PRE transgenes, is due to the interactive properties of PcG complexes, thereby facilitating pairing of two PREs on homologous chromosomes $[19,63]$. Such interactions have also been proposed to account for long-range contacts between PREs at non-homologous sites. However, it has recently been found for the Fab-7 PRE that these long-distance interactions depend not on the PRE but on the adjacent $1257 \mathrm{bp}$ insulator, $778 \mathrm{bp}$ of which is contained in the $1.6 \mathrm{~kb} \mathrm{Fab-7} \mathrm{fragment} \mathrm{studied} \mathrm{here}$ (see Additional file 1, Figure S1) [64]. It remains to be seen whether the $v g$ PRE also contains an insulator element. Our data for sites 1, 2 and 4 suggest that the inherent pairing properties of a locus may also contribute to the strength of PRE or insulator-mediated PSS. In the future, it will be very informative to use the approach described here to quantify the relative contributions of PRE sequences, insulator sequences and genomic environment to PSS using comparison of different PRE deletion constructs at these defined sites. Indeed, the distinct behavior of the two PREs at site 3, at which $F a b-7$ produced no PSS and $v g$ produced 71 fold PSS, demonstrates that the extent of somatic pairing of a region is not alone sufficient to determine PSS.

The only site at which neither PRE gave strong PSS was site 4 . Notably, this site is telomeric (Table 1), and telomeric regions have been shown to be able to recruit PcG and TrxG proteins and to induce PSS [65], thus it is surprising that no PSS was observed at this site. However, the previous study also reported that a specific subset of PcG and TrxG proteins functions at telomeres. As the endogenous locations of Fab-7 and $v g$ PREs are not at telomeres, these PREs may lack telomere-specific sequences required for correct PRE function at this location.

Furthermore, it is interesting to note that each landing site is situated in a specific chromatin type, as defined previously [66] (Table 1), which may in part account for the differences in PRE behavior seen at each site. For example, site 4, at which neither PRE showed strong silencing or PSS, is located close to 'yellow' chromatin containing active euchromatin (Table 1). Thus it is possible that, despite the telomeric location of site 4, the adjacent active-chromatin environment affects the behavior of both PREs. By contrast, site 2 is located in 'red'chromatin, also containing active euchromatin but defined by a different set of binding factors. Here, the $v g$ PRE was able to repress the $m w$ reporter, but not as strongly as at site 3, which is located in 'blue' chromatin, characterized by PcG protein binding and enrichment of the repressive chromatin marker H3K27me3. Interestingly, comparison of the deletion lines at these two sites showed that the $v g$ PRE was more sensitive to changes in DNA sequence at site 2 than at site 3 , which could be explained by the difference in chromatin type, with site 3 more strongly reinforcing $v g$ PRE silencing function because of its repressive chromatin environment. However, caution must be exercised in this interpretation, as the Fab-7 PRE showed weaker silencing and PSS at site 3 than at site 2, suggesting that for the Fab-7 PRE, some intrinsic sequence property mediates local interactions that overcome the inherently repressive nature of the chromatin environment at site 3 .

A search for local sequence features that might account for site-specific differences in PRE behavior revealed different numbers of the motifs GTGTG, GAGAG (potential GAF binding sites) and GCCAT (potential PHO binding sites) (Table 1). However, no clear correlation emerged from this analysis, again suggesting that additional sequences present at each landing site interact specifically with each PRE.

\section{$v g$ PRE deletions and the GTGT motif}

Deletion of the first $106 \mathrm{bp}$ of the $v g$ PRE led to loss of repression in homozygotes at the two sites tested, indicating that this sequence is essential for PRE function. Deletion of single motifs within this sequence showed that small deletions gave a detectable change in silencing properties. The quantitative changes in PRE output upon deletion of the $106 \mathrm{bp}$ sequence and of the short motifs were within the same range as the differences detected for a PRE of identical sequence inserted at 
different sites in the genome. This emphasizes the advantages of the site-specific approach taken here, as analysis of these deletions and mutations by a random integration approach would have been difficult to interpret.

This 106 bp sequence contains a single GAGAG motif and several GTGT motifs. GAGAG sites can be bound by the GAF [33] and PSQ [34,35] proteins. GAGAG sites or the GAF protein have been shown in different studies to have roles in both activation and silencing at PREs, or to have no effect on PRE function [57]. The GTGT motif has been identified in PREs by two independent sequence-mining approaches $[8,11]$, but has not previously been tested experimentally.

Deletion of the single GAGAG motif resulted in a marked loss of silencing in heterozygotes at both sites, thus this site seems to be involved in silencing at the $v g$ PRE, and may thus be a target for the PcG protein PSQ [34,35] or may be important for cooperative binding of GAF or PSQ with PHO, as shown for the bxd PRE [40]. However, because the deletion of the GAGA site had no effect in homozygotes, it cannot account for the marked loss of silencing we observed in homozygotes of the 106 bp deletion lines. Thus we reason that additional sequences within this region must be required for silencing.

Site-specific sequential mutation of four GTGT motifs within this $106 \mathrm{bp}$ region resulted in pronounced loss of silencing in homozygotes at both sites tested, identifying an essential role for this motif in silencing at the $v g$ PRE. Future studies will aim to elucidate the molecular mechanism by which this motif acts on $v g$ PRE silencing. Proteins that bind specifically to this sequence have not been identified to date [67]. Bioinformatic analysis of PREs that contain the GTGT motif [8] did not identify any clear correlation between the occurrence of the motif in a PRE and the class of genes with which it is associated (data not shown). Likewise, in another study [11], the authors did not report a correlation between the occurrence of this motif and a particular class of genes, but rather detected the GTGT motif to be specifically enriched in regions with a particular chromatin 'anatomy', namely, those regions enriched for PRC1 proteins and with $\mathrm{H} 3 \mathrm{~K} 4 \mathrm{Me} 3$ at the transcription start site. The motif was less enriched at transcription start sites with low H3K4Me3 enrichment, thus the GTGT motif may distinguish between different promoter architectures.

We report elsewhere that both the endogenous $v g$ PRE and the transgenic $v g$ PRE constructs are transcribed into non-coding RNA (Lempradl et al., submitted) thus the effect of the GTGT motif on silencing the $m w$ reporter in the adult eye may be mediated via transcriptional or post-transcriptional effects on non-coding RNA.
Finally, it is possible that the motif plays an indirect role in silencing, for example by affecting nucleosome positioning $[52,68]$ or by insulating the PRE from the effects of nearby chromatin [52]. Ultimately it will be essential to test the role of the $106 \mathrm{bp}$ region and the GTGT motifs within it at the endogenous $v g$ locus, using homologous recombination [69]. However this technique is time-consuming and does not lend itself readily to analysis of large numbers of constructs.

\section{Conclusions}

The ФС 31 mediated site-specific integration approach described here demonstrates the power and sensitivity of the technique for the rapid and quantitative analysis of several PREs and multiple PRE sequence variants, giving a number of unexpected insights into PRE function. This analysis revealed that the Fab-7 and $v g$ PREs have fundamentally different properties, both in terms of their interaction with the genomic environment and their inherent silencing abilities. Furthermore, we used the ФC31 tool to examine the effect of deletions and mutations in the $v g$ PRE, identifying a $106 \mathrm{bp}$ region containing a previously predicted motif, and demonstrating an essential role for this motif in silencing. Using quantitative analysis of mutated $v g$ PRE variants at identical genomic sites, we found that changes in as few as four base pairs have profound effects on PRE function, thus illustrating the sensitivity of site-directed integration as a tool for the quantitative dissection of elements of PRE design.

\section{Methods}

\section{Transgenic constructs, cloning}

The pKC27_mw vector was generated from pKC27 (Kuan-chung Su and Barry Dickson, unpublished, available on request) by replacing an AdeI-XbaI fragment containing the white promoter, with a $402 \mathrm{bp}$ AdeI-XbaI fragment of pCaSpeR4 containing the miniwhite promoter [70] (flybase: FBtp0000155). A modified version of pCaSpeR4 was used for this, from which the 42 bp between the EcoRI and SpeI sites in the polylinker had been removed by EcoRI/SpeI digestion, end-filling and re-ligation, thus removing several cloning sites that were present in $\mathrm{pKC} 27$. The transgenic PRE constructs of the Fab-7 and $v g$ PRE were obtained by PCR amplification on genomic DNA using the primers shown in Table 2. PREs, variants and control constructs were cloned with NotI/XbaI or NotI/ SpeI into the pKC27_mw vector.

\section{Site-directed mutagenesis}

Site-directed mutagenesis of PRE motifs was performed on pKC27_mw carrying the $1.6 \mathrm{~kb} v g$ PRE (QuikChange ${ }^{\circledR}$ II Site-Directed Mutagenesis Kit; Stratagene, 
Table 2 Primers used in this study

\begin{tabular}{|c|c|c|c|}
\hline Primer & Direction & Sequence $\left(5^{\prime} \rightarrow 3^{\prime}\right)$ & Enzyme site \\
\hline \multicolumn{4}{|c|}{ Primers for transgenic constructs } \\
\hline $\mathrm{vg} 1.6 \mathrm{~kb}$ & Forward & TAAAGCGGCCGCAAGTCTCCGCCCAATAAT & Notl \\
\hline$v g \Delta 100$ & Forward & TAAAGCGGCCGCAGTTTGTGTGAGAGTGAGC & Notl \\
\hline$v g \triangle 300$ & Forward & TAAAGCGGCCGCCGTAATTAAAACCGAAGG & Notl \\
\hline$v g 1.6 \mathrm{~kb}, v g \Delta 100, v g \Delta 300$ & All reverse & GCGCTTTCTAGAGAGCATATAGAAGTGGTCGAA & Xbal \\
\hline Fab-7 & Forward & TAAAGCGGCCGCGGAATTGTGTGGACGATG & Notl \\
\hline Fab-7 & Reverse & GGCGCTTACTAGTGCACAGAGAGTGCAGAAAG' & Spel \\
\hline \multicolumn{4}{|l|}{ Primers for mutagenesis } \\
\hline$v g \triangle G A G A$ & Forward & AAGAGGTTGAACCCCTTGAGGAAACCGGTTTATTTC & - \\
\hline$v g \triangle G A G A$ & Reverse & GAAATAAACCGGTTTCCTCAAGGGGTTCAACCTCTT & - \\
\hline$v g \Delta 1^{s t} \mathrm{GT}$ & Forward & CAGGAAACCGGTTTATTTCCACAACTCTGTGCGTG & - \\
\hline$v g \Delta 1^{s t} \mathrm{GT}$ & Reverse & CACGCACAGAGTTGTGGAAATAAACCGGTTTCCTG & - \\
\hline$v g \Delta 1^{\text {st }}-2^{\text {nd }} G T$ & Forward & GGTTATTTCCACAACTCCGTGTGTGCGTTTATGCC & - \\
\hline$v g \Delta 1^{\text {st }}-2^{\text {nd }} G T$ & Reverse & GGCATAAACGCACACACGGAGTTGTGGAAATAAACC & - \\
\hline$v g \Delta 1^{\mathrm{st}}-3^{\text {rd }} \mathrm{GT}$ & Forward & GTTAATTTCCACAACTCCCGTTTATGCCTGTGTGCG & - \\
\hline$v g \Delta 1^{\mathrm{st}}-3^{\text {rd }} \mathrm{GT}$ & Reverse & CGCACACAGGCATAAACGGGAGTTGTGGAAATAAAC & - \\
\hline$v g \Delta 1^{\text {st }}-4^{\text {th }} G T$ & Forward & CAACTCCCGTTTATGCCCGCTAGTTTGTGTGAGA & - \\
\hline$v g \Delta 1^{\text {st }}-4^{\text {th }} G T$ & Reverse & TCTCACACAAACTAGCGGGCATAAACGGGAGTTG & - \\
\hline
\end{tabular}

Bold sequences refer to primer tags that contain a restriction site (named in following column).

La Jolla, CA, USA) according to the manufacturers' protocol using the primers shown in Table 2 .

\section{Fly stocks and crosses}

Transgenic fly lines were obtained as described [71] by co-injection of the pKC27_mw plasmid carrying the construct of interest with the helper plasmid pKC40 (Kuan-chung Su and Barry Dickson, unpublished, available on request) encoding $\Phi C 31$ integrase into landingsite embryos. The following landing-site lines (details in Table 1) were used: sites 1 to 3: $y w ; p[w 3, y+, \operatorname{attP}] ;+$. site 4: $y w ;+; p\left[w 3, y+\right.$, attP]. Crosses to $P c^{X L 5}$ mutants were performed as described previously [36] for PRE and control lines at sites 1 to 3 , in which the landing site is on chromosome II, enabling the homozygous PRE transgene to be combined with the heterozygous $P c^{X L 5}$ mutation on chromosome III.

\section{Phenotypic analysis of flies}

Eye-pigment quantification was performed according to [72] with minor adaptations: 30-50 heads instead of 10 were used per assay to achieve robust measurements for a range of eye-pigment levels. Transgenic flies were photographed with a microscope (Lumar V12 Stereo Microscope; Carl Zeiss GmbH, Vienna, Austria) at $65 \times$ magnification, 2 seconds exposure, using Insight SPOT software (Diagnostic Instruments, Inc, Sterling Heights, MI, USA).

\section{Additional material}

Additional file 1: Figure S1. Fab-7 PRE motifs. DNA motifs in the 1.6 kb Fab-7 PRE fragment used in this study. The grey box corresponds to the highest-scoring region of the Polycomb response element (PRE) [8], and contains the minimal 219 bp PRE core sequence previously identified [56] (black line below diagram). Red line below plot indicates position of the Fab-7 insulator sequences contained in the $1.6 \mathrm{~kb}$ PRE [64]. ZESTE, GAGA factor/Pipsqueak (GAF/PSQ) and Pleiohomeotic/ Pleihomeotic-like (PHO/PHOL) DNA-binding motifs are shown. In addition, the GTGTG motif, found to be enriched in many PREs $[8,11]$, is enriched in the sequences flanking the core region.

Additional file 2: Figure S2. Eye color comparison of intact and mutated $v \boldsymbol{g}$ PREs at site 3; 5-day-old male flies are shown. (Top) A $w^{1718}$ mutant; (bottom left) homozygous $1.6 \mathrm{~kb} v \mathrm{vg}$ PRE at site 3; (bottom right) homozygous $1.6 \mathrm{~kb} v \mathrm{vg} 1^{\text {st }}-3^{\text {rd }} \mathrm{GT}$ at site 3 . The $1.6 \mathrm{~kb} v \mathrm{vg}$ PRE line has essentially identical eye color to that of the $w^{1118}$ mutant, whereas the deletion of the first three GT repeats leads to a visible increase in eye pigmentation.

\section{Acknowledgements}

We thank Sara Farina Lopez for Drosophila embryo injections, Jürgen Knoblich for providing th landing-site lines, and Barry Dickson for providing the pKC27 donor plasmid and pKC40 helper plasmid. LR, BD and SB were funded by the Austrian Academy of Sciences. $\mathrm{HO}$ was funded by an Austrian Science Fund (FWF) grant, Nr. P21525-B20 (LR).

\section{Author details}

'IMBA, Institute of Molecular Biotechnology GmBH, Dr. Bohr-Gasse 3, 1030 Vienna, Austria. ${ }^{2}$ Roche Austria GmBH, Clinical Operations, Engelhorngasse 3, 1211 Vienna, Austria. ${ }^{3}$ Department of Neurobiology, Stanford University, Stanford, CA 94305, USA. 


\section{Authors' contributions}

$\mathrm{HO}$ performed the pigment assays, designed and generated constructs and transgenic lines for the $v g$ deletion and mutation constructs, and wrote the manuscript jointly with LR. BD generated constructs and transgenic lines for full-length Fab-7, vg and control constructs. SB generated and characterized the landing-site lines. $\mathrm{LR}$ supervised $\mathrm{HO}$ and $\mathrm{BD}$, conceived and designed the study, and wrote the manuscript jointly with HO. All authors read and approved the final manuscript.

\section{Competing interests}

The authors declare that they have no competing interests.

Received: 20 December 2010 Accepted: 16 March 2011

Published: 16 March 2011

\section{References}

1. Muller J, Kassis JA: Polycomb response elements and targeting of Polycomb group proteins in Drosophila. Curr Opin Genet Dev 2006, 16(5):476-484.

2. Ringrose $L$, Paro R: Polycomb/Trithorax response elements and epigenetic memory of cell identity. Development 2007, 134(2):223-232.

3. Schwartz YB, Pirrotta V: Polycomb complexes and epigenetic states. Curr Opin Cell Biol 2008, 20(3):266-273

4. Simon J, Chiang A, Bender W, Shimell MJ, O'Connor M: Elements of the Drosophila bithorax complex that mediate repression by Polycomb group products. Dev Biol 1993, 158(1):131-144.

5. Chan CS, Rastelli L, Pirrotta V: A Polycomb response element in the Ubx gene that determines an epigenetically inherited state of repression. EMBO J 1994, 13(11):2553-2564.

6. Chiang A, O'Connor MB, Paro R, Simon J, Bender W: Discrete Polycombbinding sites in each parasegmental domain of the bithorax complex. Development 1995, 121(6):1681-1689.

7. Gindhart JG Jr, Kaufman TC: Identification of Polycomb and trithorax group responsive elements in the regulatory region of the Drosophila homeotic gene Sex combs reduced. Genetics 1995, 139(2):797-814.

8. Ringrose L, Rehmsmeier M, Dura JM, Paro R: Genome-wide prediction of Polycomb/Trithorax response elements in Drosophila melanogaster. Dev Cell 2003, 5(5):759-771.

9. Schwartz YB, Kahn TG, Nix DA, Li XY, Bourgon R, Biggin M, Pirrotta V: Genome-wide analysis of Polycomb targets in Drosophila melanogaster. Nat Genet 2006, 38(6):700-705.

10. Tolhuis B, de Wit E, Muijrers I, Teunissen $H$, Talhout W, van Steensel B, van Lohuizen M: Genome-wide profiling of PRC1 and PRC2 Polycomb chromatin binding in Drosophila melanogaster. Nat Genet 2006, 38(6):694-699.

11. Schuettengruber B, Ganapathi M, Leblanc B, Portoso M, Jaschek R, Tolhuis B, van Lohuizen M, Tanay A, Cavalli G: Functional anatomy of polycomb and trithorax chromatin landscapes in Drosophila embryos. PLOS Biol 2009, 7(1):e13.

12. Boyer LA, Plath K, Zeitlinger J, Brambrink T, Medeiros LA, Lee TI, Levine SS, Wernig M, Tajonar A, Ray MK, et al: Polycomb complexes repress developmental regulators in murine embryonic stem cells. Nature 2006, 441(7091):349-353.

13. Bracken AP, Dietrich N, Pasini D, Hansen KH, Helin K: Genome-wide mapping of Polycomb target genes unravels their roles in cell fate transitions. Genes Dev 2006, 20(9):1123-1136.

14. Lee $\mathrm{TI}$, Jenner RG, Boyer LA, Guenther MG, Levine SS, Kumar RM, Chevalier B, Johnstone SE, Cole MF, Isono K, et al: Control of developmental regulators by Polycomb in human embryonic stem cells. Cell 2006, 125(2):301-313.

15. Squazzo SL, O'Geen $H$, Komashko VM, Krig SR, Jin VX, Jang SW, Margueron R, Reinberg D, Green R, Farnham PJ: Suz12 binds to silenced regions of the genome in a cell-type-specific manner. Genome Res 2006, 16(7):890-900.

16. Schwartz YB, Kahn TG, Stenberg P, Ohno K, Bourgon R, Pirrotta V: Alternative epigenetic chromatin states of polycomb target genes. PLOS Genet 2010, 6(1):e1000805.

17. Ringrose L: Polycomb comes of age: genome-wide profiling of target sites. Curr Opin Cell Biol 2007, 19(3):290-297.

18. Schwartz YB, Pirrotta V: Polycomb silencing mechanisms and the management of genomic programmes. Nat Rev Genet 2007, 8(1):9-22.
19. Kassis JA: Unusual properties of regulatory DNA from the Drosophila engrailed gene: three "pairing-sensitive" sites within a 1.6-kb region. Genetics 1994, 136(3):1025-1038.

20. Kassis JA: Pairing-sensitive silencing, polycomb group response elements, and transposon homing in Drosophila. Adv Genet 2002, 46:421-438.

21. Poux S, Kostic C, Pirrotta V: Hunchback-independent silencing of late Ubx enhancers by a Polycomb Group Response Element. EMBO J 1996, 15(17):4713-4722.

22. Cavalli G, Paro R: The Drosophila Fab-7 chromosomal element conveys epigenetic inheritance during mitosis and meiosis. Cell 1998, 93(4):505-518.

23. Rank G, Prestel M, Paro R: Transcription through intergenic chromosomal memory elements of the Drosophila bithorax complex correlates with an epigenetic switch. Mol Cell Biol 2002, 22(22):8026-8034.

24. Maurange C, Paro R: A cellular memory module conveys epigenetic inheritance of hedgehog expression during Drosophila wing imaginal disc development. Genes Dev 2002, 16(20):2672-2683.

25. Americo J, Whiteley M, Brown JL, Fujioka M, Jaynes JB, Kassis JA: A complex array of DNA-binding proteins required for pairing-sensitive silencing by a polycomb group response element from the Drosophila engrailed gene. Genetics 2002, 160(4):1561-1571

26. Sing A, Pannell D, Karaiskakis A, Sturgeon K, Djabali M, Ellis J, Lipshitz HD, Cordes SP: A vertebrate Polycomb response element governs segmentation of the posterior hindbrain. Cell 2009, 138(5):885-897.

27. Woo CJ, Kharchenko PV, Daheron L, Park PJ, Kingston RE: A region of the human HOXD cluster that confers polycomb-group responsiveness. Cell 2010, 140(1):99-110.

28. Brown JL, Mucci D, Whiteley M, Dirksen ML, Kassis JA: The Drosophila Polycomb group gene pleiohomeotic encodes a DNA binding protein with homology to the transcription factor YY1. Mol Cell 1998, 1(7):1057-1064.

29. Mihaly J, Mishra RK, Karch F: A conserved sequence motif in Polycombresponse elements. Mol Cell 1998, 1(7):1065-1066

30. Brown JL, Fritsch C, Mueller J, Kassis JA: The Drosophila pho-like gene encodes a YY1-related DNA binding protein that is redundant with pleiohomeotic in homeotic gene silencing. Development 2003, 130(2):285-294.

31. Saurin AJ, Shao Z, Erdjument-Bromage H, Tempst P, Kingston RE: A Drosophila Polycomb group complex includes Zeste and dTAFII proteins. Nature 2001, 412(6847):655-660

32. Hur MW, Laney JD, Jeon SH, Ali J, Biggin MD: Zeste maintains repression of Ubx transgenes: support for a new model of Polycomb repression. Development 2002, 129(6):1339-1343.

33. Strutt H, Cavalli G, Paro R: Co-localization of Polycomb protein and GAGA factor on regulatory elements responsible for the maintenance of homeotic gene expression. EMBO J 1997, 16(12):3621-3632.

34. Hodgson JW, Argiropoulos B, Brock HW: Site-specific recognition of a 70base-pair element containing $d(G A)(n)$ repeats mediates bithoraxoid polycomb group response element-dependent silencing. Mol Cell Biol 2001, 21(14):4528-4543.

35. Huang DH, Chang YL: Isolation and characterization of $\mathrm{CHRASCH}$, a polycomb-containing silencing complex. Methods Enzymol 2004, 377:267-282

36. Hauenschild A, Ringrose L, Altmutter C, Paro R, Rehmsmeier M: Evolutionary plasticity of polycomb/trithorax response elements in Drosophila species. PLOS Biol 2008, 6(10):e261.

37. Dejardin J, Rappailles A, Cuvier O, Grimaud C, Decoville M, Locker D, Cavalli G: Recruitment of Drosophila Polycomb group proteins to chromatin by DSP1. Nature 2005, 434(7032):533-538.

38. Blastyak A, Mishra RK, Karch F, Gyurkovics H: Efficient and specific targeting of Polycomb group proteins requires cooperative interaction between Grainyhead and Pleiohomeotic. Mol Cell Biol 2006, 26(4):1434-1444.

39. Brown JL, Grau DJ, DeVido SK, Kassis JA: An Sp1/KLF binding site is important for the activity of a Polycomb group response element from the Drosophila engrailed gene. Nucleic Acids Res 2005, 33(16):5181-5189.

40. Kozma G, Bender W, Sipos L: Replacement of a Drosophila Polycomb response element core, and in situ analysis of its DNA motifs. Mol Genet Genomics 2008, 279(6):595-603.

41. Beuchle D, Struhl G, Muller J: Polycomb group proteins and heritable silencing of Drosophila Hox genes. Development 2001, 128(6):993-1004. 
42. Fauvarque MO, Zuber V, Dura JM: Regulation of polyhomeotic transcription may involve local changes in chromatin activity in Drosophila. Mech Dev 1995, 52(2-3):343-355.

43. Bloyer S, Cavalli G, Brock HW, Dura JM: Identification and characterization of polyhomeotic PREs and TREs. Dev Biol 2003, 261(2):426-442.

44. Martinez AM, Colomb S, Dejardin J, Bantignies F, Cavalli G: Polycomb group-dependent Cyclin A repression in Drosophila. Genes Dev 2006, 20(4):501-513.

45. Sipos L, Kozma G, Molnar E, Bender W: In situ dissection of a Polycomb response element in Drosophila melanogaster. Proc Natl Acad Sci USA 2007, 104(30):12416-12421.

46. Groth AC, Fish M, Nusse R, Calos MP: Construction of transgenic Drosophila by using the site-specific integrase from phage phiC31. Genetics 2004, 166(4):1775-1782.

47. Bischof J, Maeda RK, Hediger M, Karch F, Basler K: An optimized transgenesis system for Drosophila using germ-line-specific phiC31 integrases. Proc Natl Acad Sci USA 2007, 104(9):3312-3317.

48. Williams JA, Bell JB, Carroll SB: Control of Drosophila wing and haltere development by the nuclear vestigial gene product. Genes Dev 1991, 5(12B):2481-2495.

49. Bernard F, Lalouette A, Gullaud M, Jeantet AY, Cossard R, Zider A, Ferveur JF, Silber J: Control of apterous by vestigial drives indirect flight muscle development in Drosophila. Dev Biol 2003, 260(2):391-403.

50. Deng H, Hughes SC, Bell JB, Simmonds AJ: Alternative requirements for Vestigial, Scalloped, and Dmef2 during muscle differentiation in Drosophila melanogaster. Mol Biol Cell 2009, 20(1):256-269.

51. Guss KA, Mistry H, Skeath JB: Vestigial expression in the Drosophila embryonic central nervous system. Dev Dyn 2008, 237(9):2483-2489.

52. Hagstrom K, Muller M, Schedl P: A Polycomb and GAGA dependent silencer adjoins the Fab-7 boundary in the Drosophila bithorax complex. Genetics 1997, 146(4):1365-1380.

53. Mihaly J, Hogga I, Gausz J, Gyurkovics H, Karch F: In situ dissection of the Fab-7 region of the bithorax complex into a chromatin domain boundary and a Polycomb-response element. Development 1997, 124(9):1809-1820.

54. Lee N, Maurange C, Ringrose L, Paro R: Suppression of Polycomb group proteins by JNK signalling induces transdetermination in Drosophila imaginal discs. Nature 2005, 438(7065):234-237.

55. Oktaba K, Gutierrez L, Gagneur J, Girardot C, Sengupta AK, Furlong EE, Muller J: Dynamic regulation by polycomb group protein complexes controls pattern formation and the cell cycle in Drosophila. Dev Cell 2008, 15(6):877-889.

56. Dejardin J, Cavalli G: Chromatin inheritance upon Zeste-mediated Brahma recruitment at a minimal cellular memory module. EMBO J 2004, 23(4):857-868.

57. Ringrose $L$, Paro R: Epigenetic regulation of cellular memory by the Polycomb and Trithorax group proteins. Annu Rev Genet 2004, 38:413-443.

58. Gemkow MJ, Verveer PJ, Arndt-Jovin DJ: Homologous association of the Bithorax-Complex during embryogenesis: consequences for transvection in Drosophila melanogaster. Development 1998, 125(22):4541-4552.

59. Coulthard AB, Nolan N, Bell JB, Hilliker AJ: Transvection at the vestigial locus of Drosophila melanogaster. Genetics 2005, 170(4):1711-1721.

60. Bantignies F, Grimaud C, Lavrov S, Gabut M, Cavalli G: Inheritance of Polycomb-dependent chromosomal interactions in Drosophila. Genes Dev 2003, 17(19):2406-2420.

61. DeVido SK, Kwon D, Brown JL, Kassis JA: The role of Polycomb-group response elements in regulation of engrailed transcription in Drosophila. Development 2008, 135(4):669-676.

62. Henikoff S, Comai L: Trans-sensing effects: the ups and downs of being together. Cell 1998, 93(3):329-332.

63. Pirrotta V: Transvection and chromosomal trans-interaction effects. Biochim Biophys Acta 1999, 1424(1):M1-8.

64. Li HB, Muller M, Bahechar IA, Kyrchanova O, Ohno K, Georgiev P, Pirrotta V: Insulators, Not Polycomb Response Elements, Are Required for LongRange Interactions between Polycomb Targets in Drosophila melanogaster. Mol Cell Biol 2011, 31(4):616-625.

65. Boivin A, Gally C, Netter S, Anxolabehere D, Ronsseray S: Telomeric associated sequences of Drosophila recruit polycomb-group proteins in vivo and can induce pairing-sensitive repression. Genetics 2003 164(1):195-208.
66. Filion GJ, van Bemmel JG, Braunschweig U, Talhout W, Kind J, Ward LD, Brugman W, de Castro IJ, Kerkhoven RM, Bussemaker HJ, et al: Systematic protein location mapping reveals five principal chromatin types in Drosophila cells. Cell 2010, 143(2):212-224.

67. BKL TRANSCFAC: Transcription Factor Binding Predictions. [http://www biobase-international.com/index.php?id=transfac].

68. Kaplan N, Moore IK, Fondufe-Mittendorf Y, Gossett AJ, Tillo D, Field Y, LeProust EM, Hughes TR, Lieb JD, Widom J, et al: The DNA-encoded nucleosome organization of a eukaryotic genome. Nature 2009, 458(7236):362-366.

69. Venken KJ, Bellen HJ: Transgenesis upgrades for Drosophila melanogaster. Development 2007, 134(20):3571-3584.

70. Pirrotta V: Vectors for P-mediated transformation in Drosophila. Biotechnology 1988, 10:437-456.

71. Ringrose L: Transgenesis in Drosophila melanogaster. Methods Mol BiO 2009, 561:3-19.

72. Henikoff S, Dreesen TD: Trans-inactivation of the Drosophila brown gene: evidence for transcriptional repression and somatic pairing dependence. Proc Natl Acad Sci USA 1989, 86(17):6704-6708.

73. Williams JA, Paddock SW, Vorwerk K, Carroll SB: Organization of wing formation and induction of a wing-patterning gene at the dorsal/ventral compartment boundary. Nature 1994, 368(6469):299-305.

74. Kim J, Sebring A, Esch JJ, Kraus ME, Vorwerk K, Magee J, Carroll SB: Integration of positional signals and regulation of wing formation and identity by Drosophila vestigial gene. Nature 1996, 382(6587):133-138.

75. Philippakis AA, Busser BW, Gisselbrecht SS, He FS, Estrada B, Michelson AM, Bulyk ML: Expression-guided in silico evaluation of candidate cis regulatory codes for Drosophila muscle founder cells. PLOS Comput Biol 2006, 2(5):e53.

doi:10.1186/1756-8935-4-4

Cite this article as: Okulski et al:: Quantitative analysis of polycomb response elements (PREs) at identical genomic locations distinguishes contributions of PRE sequence and genomic environment. Epigenetics \& Chromatin 2011 4:4.

\section{Submit your next manuscript to BioMed Central and take full advantage of:}

- Convenient online submission

- Thorough peer review

- No space constraints or color figure charges

- Immediate publication on acceptance

- Inclusion in PubMed, CAS, Scopus and Google Scholar

- Research which is freely available for redistribution

Submit your manuscript at www.biomedcentral.com/submit
C Biomed Central 